Nuclear Magnetic Resonance Study of Charge-transfer Complexes of 1,3,5-Trinitrobenzene, Picric Acid, and Fluoranil with Methoxy- and Methyl-substituted Benzenes and Biphenyls. Indication of the Structure of the Complexes in Solution

By H. J. M. Andriessen," W. H. Laarhoven, and R. J. F. Nivard, Department of Organic Chemistry, Catholic University, Toernooiveld, Nijmegen, The Netherlands

Aeprinted from

JOURNAL

OF

THE CHEMICAL SOCIETY

PERKIN TRANSACTIONS II

1972 


\section{Nuclear Magnetic Resonance Study of Charge-transfer Complexes of 1,3,5-Trinitrobenzene, Picric Acid, and Fluoranil with Methoxy- and Methyl-substituted Benzenes and Biphenyls. Indication of the Structure of the Complexes in Solution}

By H. J. M. Andriessen * W. H. Laarhoven, and R. J. F. Nivard, Department of Organic Chemistry Catholic University, Toernooiveld, Nijmegen, The Netherlands

Association constants for the charge-transfer complexes formed between 1.3,5-trinitrobenzene, fluoranil, or picric acid and methoxy- and methyl-substituted benzenes and biphenyls have been determined from n.m.r. chemical shift measurements. With some exceptions the $\log K$ values of these complexes vary linearly with the energy of the charge-transfer transition.

For complexes of non-hindered biphenyl donors a larger shift of the acceptor protons in pure complex $\left(\Delta_{0}\right)$ is found than for the complexes of the corresponding substituted benzenes. It is shown that this increase in $\Delta_{0}$ is only due to a ring-current effect of the second ring of the biphenyl donor. For several model structures of the complex this effect has been calculated. The agreement for the model with a coaxial arrangement of donor and acceptor is very satisfactory. The conclusion is that Mulliken's principle of maximum overlap does indeed apply for these complexes.

CHARge-TRANSFER complexes have been of interest recently. ${ }^{1}$ Since Mulliken founded a theoretical basis for the quantum-mechanical description of chargetransfer interaction ${ }^{2}$ and formulated his 'overlap and orientation ' principle ${ }^{3}$ there has been considerable discussion about the structure of charge-transfer complexes in solution. . $^{4-9}$

The crystal structures of a number of complexes between $\pi$-donors and $\pi$-acceptors are known. ${ }^{10-13}$ The planes of donor and acceptor molecules are parallel

1 See e.g., R. Foster, 'Organic Charge-Transfer Complexes,' Academic Press, London and New York, 1969.

R. S. Mulliken, J. Amer. Chem. Soc., 1962, 74, 811.

3 R. S. Mulliken, Rec. Trav, chim., 1956, 75, 845.

4 A. H. Ewald, Trans. Faraday Soc., 1968, 64, 733.

5 E. Shilton and C. H. J. Wells, J. Chem. Soc. $(B), 1970$, 1613.

- H. Kuroda, I. Kemoto, and H. Akamatu, Bull. Chem. Soc. Japan, 1960, 39, 1842. but a relative orientation according to the maximumoverlap principle is not generally observed. Care should be taken to extrapolate properties of chargetransfer complexes from the solid phase to solution. It has been reported that the molecular centres of the components of the chloranil-hexamethylbenzene complex in solution might not be superimposed.4 There is still considerable uncertainty about the structure of charge-transfer complexes in solution.

In certain cases, n.m.r. spectroscopy can be used to

7 G. K. Vemulapalli, J. Amer. Chem. Soc., 1970, 92, 7589.

B J. L. Lippert, M. W. Hanna, and P. J. Trotter, J. Amer. Chem. Soc., 1970, 91, 4035.

B E. M. Voigt, J. Amer. Chem. Soc., 1964, 86, 3930.

10 N. D. Jones and R. E. Marsh, Acta Cryst., 1962, 15, 809.

11 A. Hanson, Acta Cryst., 1963, 16, 1147.

12 D. S. Brown, S. C. Wallwork, and A. Wilson, Acta Cryst., 1964, 17, 168.

1s S. C. Wallwork, J. Chem. Soc., 1961, 494. 
study charge-transfer complexes in solution. ${ }^{14,15} A$ priori it must be possible to obtain information about the structure of a complex from chemical-shift measurements. However, the origin of the changes in position of n.m.r. signals by complexation is not fully understood. ${ }^{16,17}$

Generally the shift in position of the acceptor signal is recorded in solutions in which the donor is in large excess. ${ }^{15}$ The acceptor signal moves to higher field on complexation. By analogy with the contributions to the solvent shift for solute molecules, ${ }^{18}$ the shift of the acceptor protons in pure complex $\delta^{\mathbf{A}}{ }_{\mathbf{A D}}$ relative to the shift of the pure acceptor in solution $\delta^{\Delta}{ }_{0}$ can be expressed by equation (1). Here $-\delta^{c}$ is the difference between

$$
\delta^{A_{0}}-\delta^{A}{ }_{A D}=\Delta_{0}=\delta^{c}{ }_{w}+\delta^{c}{ }_{e}+\delta^{c}{ }_{a}
$$

the contribution of dispersion forces to the chemical shift of the acceptor in the complex and the acceptor in solution.

$-\delta^{c}{ }_{\theta}$ Is the difference between the contribution of an electric field (the 'reaction field ' generated by a permanent dipole, e.g., the dipole of the complex) to the chemical shift of the acceptor in complex and the acceptor in solution.

It has been reported ${ }^{10}$ that, in addition to chargetransfer forces, a considerable part of the stabilisation energy and dipole moment of the complex may be due to polarisation of the donor by local dipoles of the acceptor.

$-\delta_{\mathrm{B}}^{\mathrm{c}}$ Arises from the anisotropy in the molecular susceptibility of the donor molecule in the complex. A comprehensive list of calculated shielding contributions, based on the Johnson-Bovey equations, ${ }^{20}$ for protons at various orientations relative to a benzene ring provides the possibility for an estimation of $\delta_{a}^{c}$ in complexes with aromatic donor molecules and varying conformations. 21

With normal intermolecular distances for the trinitrobenzene-benzene complex an upfield shift of approximately 0.4 p.p.m. is calculated (see below) for various positions of the components in the complex. For complexes of several methylbenzenes an approximately constant value of $\Delta_{0}$ (1-1 p.p.m.) is observed. ${ }^{15}$ So a substantial part of the shift should arise from the contributions $\delta^{\mathrm{c}}{ }_{\mathrm{e}}$ and $\delta_{\mathrm{w}}^{\mathrm{c}}$. That ring currents are important, however, is apparent from the large $\Delta_{0}$ value (1.7 p.p.m.) for the complex of trinitrobenzene and $\alpha$-methylnaphthalene. ${ }^{22}$

If in a set of similar complexes in the same solvent dispersion interactions, polarisation forces, and charge-

14 M. W. Hanna and A. L. Ashbaugh, J. Phys. Chem., 1964, 68,811 .

is R. Foster and C. A. Fyfe, Trans. Faraday Soc., 1965, 61, 1626.

10 A. A. Sandoval and M. W. Hanna, J. Phys. Chem., 1966, 70, 1202 .

i7 R. Foster and C. A. Fyfe, in ' Progress in Nuclear Magnetic Resonance Spectroscopy,' vol. IV, eds. J. W. Emsley, J. Feeney, and L. H. Sutcliffe, Pergamon, London, 1969.

18 A. D. Buckingham, T. Schaeffer, and W. G. Schneider, J. Chem. Phys., 1960, 32, 1227. transfer interactions remain constant, then the contributions of $\delta^{c}{ }^{c}$ and $\delta^{c}{ }_{w}$ to $\Delta_{0}$ remain constant, and we can write equation (2). Here $\Delta_{\mathrm{i}}$ is the constant contribution

$$
\Delta_{0}=\Delta_{\mathrm{i}}+\Delta_{\mathrm{a}}
$$

of the interactions mentioned above and $\Delta_{\mathrm{a}}$ is the contribution to $\Delta_{0}$ of ring-current effects.

Based on this assumption the following approximation was used in a study of the structure of charge-transfer complexes. In several series of complexes with simple aromatic and comparable biphenyl donors, those biphenyl complexes were selected by analysis of equilibrium constants in which the presence of an extra aromatic ring does not vary the structure of the complex. In those cases differences in $\Delta_{0}$ found for biphenyl and comparable 'half' molecules (simple aromatic molecules) can be wholly ascribed to the ring-current influence of the added ring, and can be compared with values calculated for various structural models.

Our investigations concern complexes with trinitrobenzene, picric acid, or fluoroanil as acceptor. As donor molecules were used methylbenzenes, biphenyl or methylbiphenyls, and the corresponding methoxyderivatives, anisole, methylanisoles, or methyl-4,4'dimethoxybiphenyls.

\section{EXPERIMENTAL}

The methylbenzenes were commercial samples generally of high purity and were used as such or freshly distilled. The anisoles were prepared from their corresponding phenols by methylation with dimethyl sulphate. The biphenyls were prepared from the corresponding bromobenzenes or -anisoles by the procedure described; ${ }^{23}$ their purity was checked by m.p., refractive index, and n.m.r.

Trinitrobenzene was recrystallized twice from ethanol and once from carbon tetrachloride and had m.p. 124$124.5{ }^{\circ} \mathrm{C}$. Picric acid, recrystallized twice from water, had m.p. 123-124 ${ }^{\circ} \mathrm{C}$. Fluoranil, twice sublimed in vacuo, had m.p. $178^{\circ} \mathrm{C}$.

All n.m.r. spectra were measured at $20^{\circ} \mathrm{C}$ with a Varian HA 100 spectrometer. ${ }^{1} \mathrm{H}$ N.m.r. spectra were measured at $100 \mathrm{MHz}$ with $5 \%$ tetramethylsilane as internal reference. The estimated accuracy of the line positions is $0.2 \mathrm{~Hz}$. ${ }^{18} \mathrm{~F}$ N.m.r. spectra were measured at $94 \cdot 102 \mathrm{MHz}$. In this case a concentrated solution of fluoranil in dichloroethane was used as external reference. Changes in the line position of the acceptor were measured with the sideband technique. The estimated accuracy is $\mathbf{1 ~} \mathbf{H z}$.

Initial association constants $\left(K^{\mathrm{AD}}\right)$ and values of $\Delta_{0}$ were calculated by the method described ${ }^{15}$ from relation (3)

$$
\Delta /\left[D_{0}\right]=-K^{\Delta D} \Delta+K^{A D} \Delta_{0}
$$

19 R. J. W. Le Fèvre, D. V. Radford, and P. J. Stiles, I. Chem, Soc. $(B), 1968,1297$.

20 C. E. Johnson and E. A. Bovey, J. Chem. Phys., 1958, 29, 1012.

${ }_{21}$ J. W. Emsley, J. Feeney, and L. H. Sutcliffe, ' High Resolution Nuclear Magnetic Resonance Spectroscopy,' Pergamon, Oxford, 1965, vol. I, p. 595.

sa M. D. Johnston, F. P. Gasparro, and F. D. Kuntz, J. Amer. Chem. Soc., 1969, 91, 5715.

${ }^{28}$ C. E. Castro, L. J. Andrews, and R. M. Keefer, I. Amer. Chem. Soc., 1958, 80, 2332. 
in which $\Delta$ is the measured value. For the estimation of $95 \%$ confidence limits of $K^{\Delta D}$ and $\Delta_{0}$ equation (4) was used. ${ }^{14}$ It was assumed that the error in $1 /\left[D_{0}\right]$ is much

$$
1 / \Delta=\left(1 / K^{\mathrm{AD}} \Delta\right)\left(1 /\left[D_{0}\right]\right)+1 / \Delta_{0}
$$

smaller than that in $1 / \Delta_{0}$, and that the errors are independent. ${ }^{24}$

The concentrations of the acceptors trinitrobenzene, picric acid, and fluoranil were $4 \times 10^{-3}, 6 \times 10^{-3}$, and $6 \times 10^{-3} \mathrm{M}$ respectively.

For strong complexes $\left(K^{\mathrm{AD}}>5\right)$ the concentrations of the donors were in the range $0.02-0.6 \mathrm{M}$. For the complexes with $K^{\mathrm{AD}}<5$ the concentrations of the donors varied between 0.16 and $1.4 \mathrm{M}$.

In all cases the data plotted according to equation (3) provided straight lines, indicating the absence of termolecular complexes. ${ }^{25}$ Carbon tetrachloride, distilled before use, was used as solvent. U.v. and visible spectra were recorded with a Beckman DK2A spectrophotometer.

\section{RESULTS AND DISCUSSION}

The results are compiled in Tables $\mathbf{1 - 5}$.

Association Constants.-For the complexes of all three acceptors with the anisoles and benzenes, an

\section{TABLE 1}

Values of $K^{\mathrm{AD}}$ for donor-trinitrobenzene complexes in carbon tetrachloride at $20{ }^{\circ} \mathrm{C}$, together with the chemical shift of the measured nucleus in solutions of the pure complex relative to the chemical shift in solution of the pure acceptor $\left(\Delta_{0}\right)$

\begin{tabular}{|c|c|c|c|}
\hline Donor & $\begin{array}{c}K^{\Delta \mathrm{D}_{\mathrm{r}} /} \\
\mathrm{kg} \mathrm{mol}\end{array}$ & $\Delta_{0} / \mathrm{Hz}$ & $\begin{array}{c}10^{-4} v_{\mathrm{CT}} / \\
\mathrm{cm}^{-1}\end{array}$ \\
\hline (1) Anisole & $1.56 \pm 0.12$ & $91 \pm 5$ & $2 \cdot 80$ \\
\hline (2) 2-Methylanisole & $1.99 \pm 0.17$ & $101 \pm 6$ & $2 \cdot 71$ \\
\hline (3) 3-Methylanisole & $2.01 \pm 0.09$ & $95 \pm 3$ & $\mathbf{2} \cdot \mathbf{7 0}$ \\
\hline (4) 4-Methylanisole & $0 \cdot 34$ & 82 士 6 & $\mathbf{2} \cdot 62$ \\
\hline (6) 2,3-Dimethylanisole & 0.15 & $100 \pm 4$ & $2 \cdot 64$ \\
\hline (6) 2,4-Dimethylanisole & $0 \cdot 18$ & 93 主 3 & 2.54 \\
\hline (7) 2,5-Dimethylanisole & 3-06 & $91 \pm 4$ & $2 \cdot 58$ \\
\hline (8) 2,6-Dimethylanisole & $\mathbf{2} \cdot \mathbf{5}$ & $81 \pm 2$ & 2.82 \\
\hline (9) 3,4-Dimethylanisole & $=0.12$ & 89 & $2 \cdot 56$ \\
\hline (10) 3,5-Dimethylanisole & $3.17 \pm 0.36$ & $85 \pm$ & 2.63 a \\
\hline $\begin{array}{l}\text { (11) } 2,4,6 \text {-Trimethylanisole } \\
\text { (12) 4,4'-Dimethoxybiphenyl }\end{array}$ & $3 \cdot 20 \pm 0 \cdot 18$ & $80 \pm 2$ & $\begin{array}{l}2 \cdot 75 \\
2 \cdot 32\end{array}$ \\
\hline $\begin{array}{l}\text { (13) 2,2'-Dimethyl-4,4'-di- } \\
\text { methoxybiphenyl }\end{array}$ & $3-17 \pm 0-17$ & $56 \pm 2$ & $2 \cdot 52$ \\
\hline $\begin{array}{l}\text { (14) 3,3'-Dimethyl-4,4, } \text { 4 }^{\prime} \text {-di- } \\
\text { methoxybiphenyl }\end{array}$ & $9 \cdot 32 \pm 0 \cdot 70$ & $111 \pm 4$ & $2 \cdot 22$ \\
\hline $\begin{array}{l}\text { (15) } 2,2^{\prime}, 5,5^{\prime} \text {-Tetramethyl-4,4'- } \\
\text { dimethoxybiphenyl }\end{array}$ & $2 \cdot 11 \pm 0.37$ & $65 \pm 5$ & 2.43 \\
\hline $\begin{array}{c}\text { (16) } 2,2^{\prime}, 6,6^{\prime}-\text { Tetramethyl }^{-4,4^{\prime}-} \\
\text { dimethoxybiphenyl }\end{array}$ & $2 \cdot 30$ & $41 \pm 3$ & 2.55 \\
\hline $\begin{array}{c}\text { (17) } 3,3^{\prime}, 5,5^{\prime} \text {-Tetramethyl-4,4'- } \\
\text { dimethoxybiphenyl }\end{array}$ & \pm 0.19 & $\mathbf{9 9} \pm \mathbf{1}$ & $2 \cdot 43$ \\
\hline
\end{tabular}

increase in $K^{\mathrm{AD}}$ with increasing methylation of the donor component is observed. Methyl substitution

$2 s$ W. H. Laarhoven and R. J. F. Nivard, Rec. Trav. chim., $1965,84,1478$.

${ }_{25}$ B. Dodson, R. Foster, A. A. S. Bright, M. I. Foreman, and J. Gorton, $J$. Chem. Soc. $(B), 1971,1283$.

${ }^{26}$ P. H. Emslie, R. Foster, J. W. Morris, and D. E. Twiselton, J. Chem. Soc. (B), 1969, 1161 .

${ }_{27}$ R. E. Merrifield and W. D. Phillips, J. Amer. Chem. Soc., $1958,80,2778$. lowers the ionisation potential of a donor and hence increases its electron-donating ability. ${ }^{26,27}$ The values of the association constants for the complexes of donor 8 are lower than those of its isomers; also with (11) as a donor low $K^{\Delta D}$ values are found. In addition the

\section{TABLE 2}

Values of $K^{\Delta D_{r}}$ and $\Delta_{0}$ for the complexes of picric acid with some of the donors of Table 1 , measured in $\mathrm{CCl}_{4}$ at $20^{\circ} \mathrm{C}$

\begin{tabular}{|c|c|c|}
\hline Donor & $\begin{array}{c}K^{\Delta \mathrm{D}_{\mathrm{r}} /} \\
\mathrm{kg} \mathrm{mol}^{-1}\end{array}$ & $\Delta_{0} / \mathrm{Hz}$ \\
\hline (1) Anisole & $1.82 \pm 0.15$ & $88 \pm 3$ \\
\hline 2-Methylanisole & $2.08 \pm 0.18$ & $98 \pm 4$ \\
\hline (3) 3-Methylanisole & $2.13 \pm 0.15$ & $89 \pm 3$ \\
\hline (5) 2,3-Dimethylanisole & $3 \cdot 13 \pm 0.15$ & $\mathbf{9 5} \pm \mathbf{3}$ \\
\hline (8) 2,6-Dimethylanisole & $2.29 \pm 0.15$ & $77 \pm 2$ \\
\hline (9) 3,4-Dimethylanisole & $3.52 \pm 0.20$ & $89 \pm 2$ \\
\hline (10) 3,5-Dimethylanisole & $4.04 \pm 0.32$ & $77 \pm 3$ \\
\hline (11) 2,4,6-Trimethylanisole & $3.19 \pm 0.14$ & $72 \pm 1$ \\
\hline $\begin{array}{l}\text { (13) } 2,2^{\prime} \text {-Dimethyl-4,4'-dimethoxy- } \\
\text { biphenyl }\end{array}$ & $2 \cdot 49 \pm 0.11$ & $54 \pm 1$ \\
\hline $\begin{array}{l}\text { (14) 3,3'-Dimethyl-4,4'-dimethoxy- } \\
\text { biphenyl }\end{array}$ & $9.48 \pm 0.78$ & $102 \pm 4$ \\
\hline $\begin{array}{l}\text { (15) } 2,2^{\prime}, 5,5^{\prime} \text {-Tetramethyl-4,4'-di- } \\
\text { methoxybiphenyl }\end{array}$ & $1.80 \pm 0.22$ & $65 \pm 4$ \\
\hline $\begin{array}{l}\text { (16) } 2,2^{\prime}, 6,6^{\prime} \text {-Tetramethyl-4,4'-di- } \\
\text { methoxybiphenyl }\end{array}$ & $2 \cdot 37 \pm 0 \cdot 22$ & $35 \pm 2$ \\
\hline $\begin{array}{l}\text { (17) } 3,3^{\prime}, 5,5^{\prime} \text {-Tetramethyl-4,4'-di- } \\
\text { methoxybiphenyl }\end{array}$ & $7 \cdot 17 \pm 0.45$ & $97 \pm 3$ \\
\hline
\end{tabular}

values of $\nu_{\mathbb{C T}}$ are relatively large in these complexes. In these donors the methoxy-group is forced out of the plane of the benzene ring. ${ }^{28-31}$ The conjugation of the methoxy-group with the benzene ring is reduced by this effect, so the ionisation potential is increased.

The values of $K^{\mathrm{AD}}$ of the complexes of the nonhindered biphenyl donors [(14), (17), (31), (32), and (33)] are 3-4 times as large as the values of $K^{\Lambda \mathrm{D}}$ for the complexes of the corresponding ' half' molecules [(2), (8), (19), and (20)]. These donors have a much lower ionisation potential owing to a substantial increase in the $\pi$-system. In addition there might be a statistical factor involved, ${ }^{26,32}$ because of the presence of two donor sites in the biphenyl moiety. In the present case, however, the two phenyl rings are conjugated and in close proximity. Hence the statistical factor will be close to unity. For the o-methylbiphenyls [(13), (15), (16), (34), (35), and (36)] a coplanar conformation is no longer possible. The conjugation between the two benzene rings is considerably reduced. The ionisation potential of these donors is higher and hence the association constant smaller.

A second effect on the association constant in the hindered biphenyls is due to a restriction of close approach between donor and acceptor in the conformation most suitable for charge-transfer. This may be called

${ }_{28}$ J. P. Schaefer and T. J. Miraglia, J. Amer. Chem. Soc., $1964,86,64$.

${ }^{29}$ A. Balasubramanian, J. C. Pearden, W. F. Forbes, and N. F. Cheetham, Canad. J. Chem., 1965, 43, 2603.

${ }_{30}$ M. J. Aroney, M. G. Cortfield, and R. J. W. Le Fèvre, J. Chem. Soc., 1964, 2954.

${ }^{31}$ A. Zweig, J. Phys. Chem., 1963, 67, 506. 630 . 
TABLE 3

Values of $K^{\mathrm{AD}}, \Delta_{0}$, and $\nu_{\mathrm{CT}}$ for the complexes of trinitrobenzene with various donors, measured in $\mathrm{CCl}_{4}$ at $20{ }^{\circ} \mathrm{C}$

\begin{tabular}{|c|c|c|c|c|c|c|}
\hline & Donor & $K^{\Delta D_{x} / \mathrm{kg} \mathrm{mol}^{-1}}$ & $\Delta_{0} / H_{z}$ & $10^{-4} v_{\mathrm{CT}} / \mathrm{cm}^{-1}$ & $K^{\mathrm{AD}} \mathrm{D}_{\mathrm{v}} / \mathrm{kg} \mathrm{mol}^{-1}$ & $\Delta_{0} / H_{z}$ \\
\hline$(19$ & Benzene & $0.59 \pm 0.03$ & $126 \pm 4$ & 3.54 & $0.58^{a}$ & $126^{6}$ \\
\hline$(20$ & Toluene & $0.95 \pm 0.04$ & $111 \pm 3$ & 3.27 & $0.80^{\circ}$ & $120^{\circ}$ \\
\hline (21 & 0 -Xylene & $1.28 \pm 0.18$ & $109 \pm 8$ & 3-18 & $1 \cdot 34^{a}$ & $112^{b}$ \\
\hline$(22$ & $m$-Xylene & $1.36 \pm 0.06$ & $101 \pm 2$ & $3 \cdot 18$ & $1 \cdot 26^{a}$ & $108^{b}$ \\
\hline$(23$ & $p$-Xylene & $1.22 \pm 0.08$ & $104 \pm 3$ & $3 \cdot 19$ & $1 \cdot 13$ a & $113^{6}$ \\
\hline$(24$ & Mesitylene & $1.72 \pm 0.18$ & $97 \pm 5$ & $\mathbf{3} \cdot 00$ & $1 \cdot 60^{a}$ & $102^{b}$ \\
\hline 25 & 1,2,4-Trimethylbenzene & $2.03 \pm 0.29$ & $104 \pm 6$ & 3.07 & 1.98 & $102^{b}$ \\
\hline$(26$ & 1,2,3-Trimethylbenzene & $2 \cdot 11 \pm 0.11$ & $107 \pm 4$ & 3.09 & $1.88^{\circ}$ & $108^{b}$ \\
\hline 27 & $1,2,4,5$-Tetramethylbenzene & $2 \cdot 84 \pm 0.28$ & 102 土 5 & $2 \cdot 94$ & $2 \cdot 74^{\alpha}$ & $103^{b}$ \\
\hline 28 & $1,2,3,6$-Tetramethylbenzene & $3.27 \pm 0.06$ & $98 \pm 1$ & $\mathbf{2} \cdot \mathbf{8 7}$ & $2 \cdot 85^{a}$ & $112^{b}$ \\
\hline 29 & Pentamethylbenzene & 5.11士0.22 & $104 \pm 2$ & $2 \cdot 67$ & $4 \cdot 07$ a & $110^{\circ}$ \\
\hline 30 & Hexamethylbenzene & $7.51 \pm 0.66$ & $109 \pm 5$ & $2 \cdot 53$ & $6.90^{\circ}$ & $108^{b}$ \\
\hline (31 & Biphenyl & $1.75 \pm 0.14$ & $130 \pm 5$ & $3.03 d$ & $1.7^{\circ} \mathrm{C}-\mathrm{c}-\mathrm{c}$ & \\
\hline 02 & 3,3'-Dimethylbiphenyl & $3.80 \pm 0.18$ & $119 \pm 3$ & $\mathbf{2 \cdot 7 4}$ & $3 \cdot 4^{\circ}$ & \\
\hline$(3:$ & 4,4'-Dimethylbiphenyl & $4.41 \pm 0.23$ & $117 \pm 3$ & $\mathbf{2} \cdot \mathbf{6 3}$ & 4-1. & \\
\hline & $\mathbf{2}, \mathbf{2}^{\prime}$-Dimethylbiphenyl & $1-03 \pm 0.07$ & $87 \pm 4$ & $3 \cdot 17$ & $0.7^{\circ}$ & \\
\hline (3) & $2,2^{\prime}, 4,4^{\prime}, 6,6^{\prime}$-Hexamethylbiphenyl & $0.37 \pm 0.02$ & $80 \pm$ & 2.94 & $<0.2^{c}$ & \\
\hline & $2,2^{\prime}, 6,6^{\prime}$-Tetramethylbiphenyl & $0.43 \pm 0.02$ & $76 \pm 4$ & $3 \cdot 12$ & $<0.2^{\circ}$ & \\
\hline
\end{tabular}

a Data from ref. 26, converted to $20^{\circ} \mathrm{C}$ with published values of $\Delta H$ from ref. 36. Values of $\Delta H$ for isomers were taken equal. b Calculated from data of ref. 26 at $100 \mathrm{MHz}$. "Calculated from data of ref. 26, expressed in $\mathrm{kg} \mathrm{mol}^{-1}$ at $20^{\circ} \mathrm{C}$. d Determined from a plot of the values of $v_{C T}$ against the photoionisation potentials of the methylbenzenes (R. Bralsford, P. V. Harris, and W. C. Price, Proc. Roy. Soc., 1960, A, 628, 459). The photoionisation potential of biphenyl is $8.27 \mathrm{eV}$ (K. Watanabe, T. Nakayama, and J. Matte, J. Quantum Spectroscopy Radiation Transfer, 1962, 2, 369).

\section{TABLE 4}

Values of $K^{\mathrm{AD}}$ and $\Delta_{0}$ for the complexes of picric acid with some of the donors of Table 3 , measured in $\mathrm{CCl}_{4}$ at $20{ }^{\circ} \mathrm{C}$

(19) Benzene Donor

(22) $m$-Xylene

(23) $p$-Xylene

(24) Mesitylene

(25) 1,2,4-Trimethylbenzene

(27) 1,2,4,5-Tetramethylbenzene

(30) Hexamethylbenzene

(31) Biphenyl

(32) 3,3'-Dimethylbiphenyl

(33) 4,4'-Dimethylbiphenyl

(34) 2,2'-Dimethylbiphenyl

(36) $2,2^{\prime}, 6,6^{\prime}$-Tetramethylbiphenyl

\begin{tabular}{rc}
$K^{A D_{z}} / \mathrm{kg} \mathrm{mol}^{-1}$ & \multicolumn{1}{c}{$\Delta_{0} / \mathrm{Hz}$} \\
$0.63 \pm 0.04$ & $131 \pm 6$ \\
$1.29 \pm 0.12$ & $112 \pm 4$ \\
$1.20 \pm 0.09$ & $119 \pm 4$ \\
$1.86 \pm 0.15$ & $101 \pm 4$ \\
$1.68 \pm 0.12$ & $113 \pm 3$ \\
$2.68 \pm 0.14$ & $106 \pm 3$ \\
$6.34 \pm 0.27$ & $101 \pm \mathbf{2}$ \\
$1.94 \pm 0.09$ & $130 \pm 2$ \\
$3.02 \pm 0.21$ & $126 \pm 4$ \\
$3.88 \pm 0.38$ & $122 \pm 6$ \\
$0.97 \pm 0.15$ & $92 \pm 9$ \\
$0.37 \pm 0.06$ & $88 \pm 6$
\end{tabular}

TABLE 5

Values of $K^{\mathrm{AD}}, \Delta_{0}$ (for ${ }^{19} \mathrm{~F}$ resonance), and $\nu_{\mathrm{CT}}$ for complexes formed between fluoranil and some donors in carbon tetrachloride at $20^{\circ} \mathrm{C}$

\begin{tabular}{|c|c|c|c|}
\hline Donor & 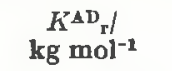 & $\Delta_{0} / \mathrm{Hz}$ & $\begin{array}{c}10^{-4} \mathrm{v}_{\mathrm{CT}} / \\
\mathrm{cm}^{-1}\end{array}$ \\
\hline Anisole & $1.41 \pm 0.10$ & $277 \pm 11$ & $2 \cdot 34$ \\
\hline Iethylanisole & $2.21 \pm$ & $242 \pm$ & \\
\hline ylanisole & $2.82 \pm 0.24$ & $337 \pm$ & $2 \cdot 23$ \\
\hline & & $305 \pm$ & $2 \cdot 12$ \\
\hline isole & $6 \pm$ & $300 \pm$ & $\boldsymbol{a}$ \\
\hline & & $327=$ & $1 \cdot 98$ \\
\hline & $\mathbf{3}$ & 330 & 2.06 \\
\hline & $1 \cdot 79 \pm$ & 297 & $2 \cdot 53$ \\
\hline & 3. & 36 & 2.01 \\
\hline & & $\mathbf{3 5}$ & $a$ \\
\hline $\begin{array}{l}\text { anisole } \\
\text { biphenyl }{ }^{b}\end{array}$ & 50 & 316 & $\begin{array}{l}2 \cdot 37 \\
1 \cdot 82\end{array}$ \\
\hline $\begin{array}{l}\text { 2,2'-Dimethyl-4,4 } \\
\text { methoxybiphenyl }\end{array}$ & 1 & 278 土 & 0 \\
\hline$-4,4^{\prime}$-di- & $10.5 \pm 3.0$ & $195 \pm 40$ & $1 \cdot 6$ \\
\hline $\begin{array}{l}2,2^{\prime}, 5,5^{\prime}-\mathrm{T} \\
\text { dimetho }\end{array}$ & $1.91 \pm 0.16$ & $283 \pm 20$ & 1.9 \\
\hline $\begin{array}{l}2,2^{\prime}, 6,6^{\prime} \text {-Tet } \\
\text { dimethox }\end{array}$ & & $323 \pm$ & $2 \cdot 14$ \\
\hline $\begin{array}{c}3^{\prime}, 5,5^{\prime} \text {-Tetramethyl-4, } \\
\text { dimethoxybiphenyl }\end{array}$ & & $289 \pm 1$ & 1.9 \\
\hline
\end{tabular}

- The position of the lowest-energy charge-transfer band could not be determined owing to strong overlap with the high energy charge-transfer band. Too insoluble to measure. the primary steric effect. ${ }^{23,26}$ Similar reductions in the value of the association constant have been observed in complexes of tetracyanoethylene with a series of alkylated 4,4'-dimethoxystilbenes having increasing lack of coplanarity. ${ }^{24}$

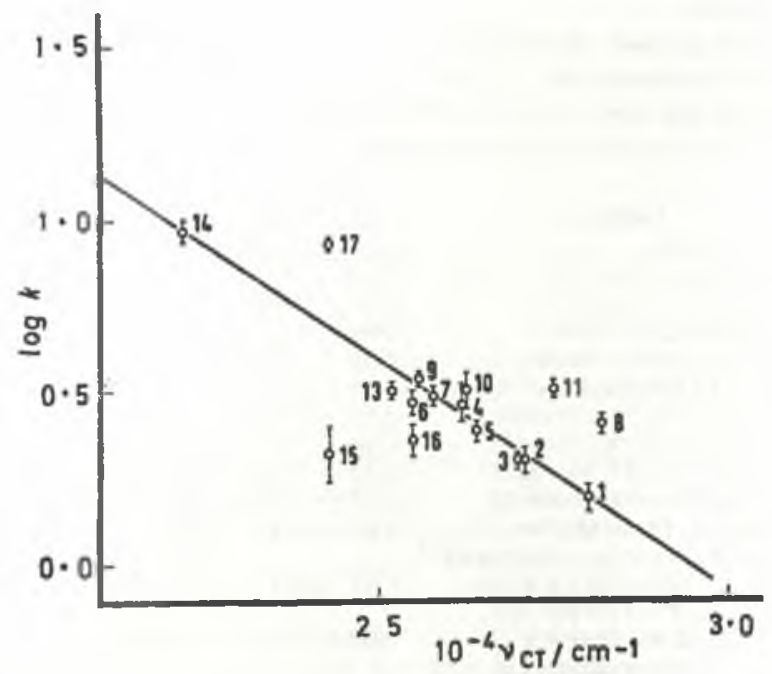

Figure 1 Plots of $\log K$ for a series of trinitrobenzene complexes against the energy $\left(\nu_{\mathrm{CT}}\right)$ of the charge-transfer transition; data from Table 1

Figures 1-3 show plots of $\log K$ against the energy $v_{\mathrm{CT}}$ of the charge-transfer transition (generally proportional to the ionisation potential) for several series of complexes (data from Tables 1-3). The straight lines drawn in the Figures are calculated, the results for the non-planar donors $[(8)$ and $(11)$ in the anisole, (13), (15), (16), (17), (34), (35), and (36) in the biphenyl series] being neglected. Correlation coefficients are $0.984,0.981$, and 0.971 , respectively.

Flurry introduced a semi-empirical molecular orbital 
theory for charge-transfer complexes. ${ }^{23,34}$ The chargetransfer interaction between donor and acceptor was assumed to arise primarily from the interaction of the highest occupied $\mathrm{MO}$ of the donor $(\mathrm{HOMO})_{D}$ with the lowest empty MO of the acceptor (LEMO) $)_{\mathbf{A}}$. The resulting complex orbital $\psi_{D A}$ is assumed to be a linear

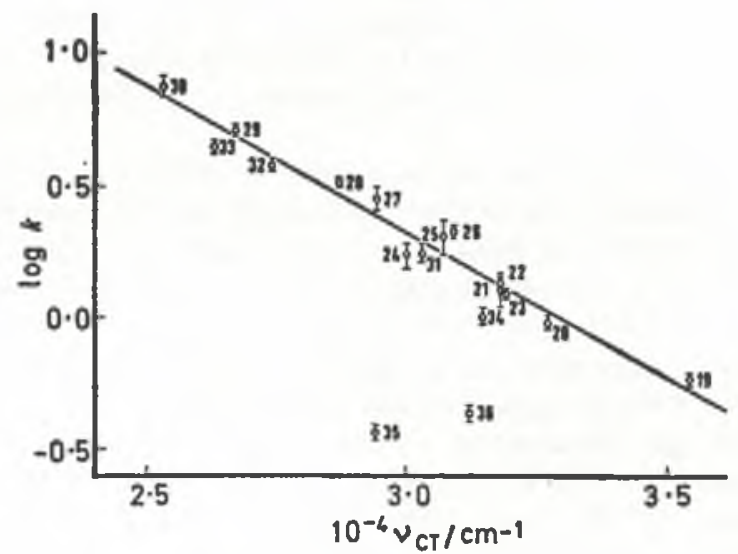

FIGURE 2 Plots of $\log K$ for a series of trinitrobenzene complexes against the energy $\left(\mathrm{V}_{\mathrm{CI}}\right)$ of the charge-transfer transition; data from Table 3

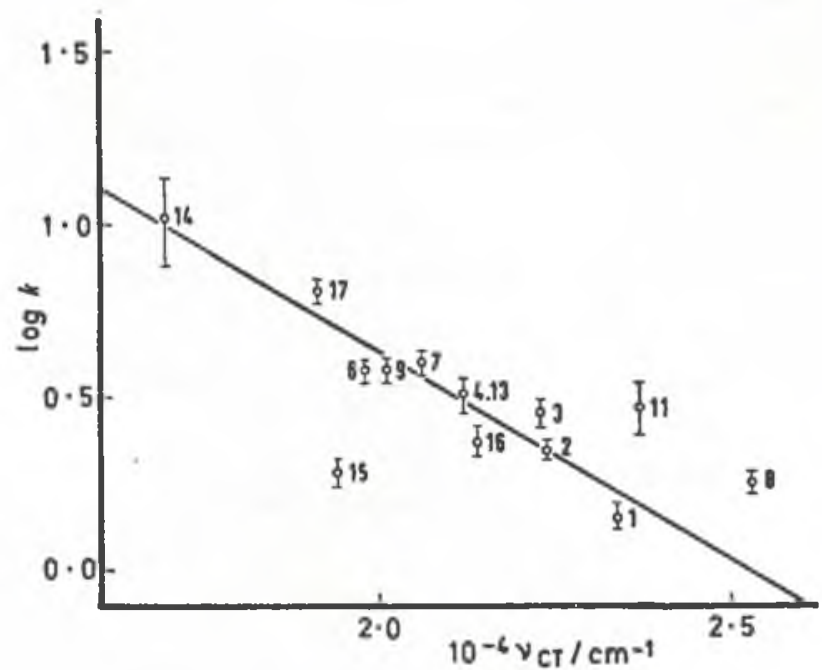

Figure 3 Plots of $\log K$ for a series of fluoranil complexes against the energy $\left(v_{\mathrm{CT}}\right)$ of the charge-transfer transition; data from Table 5

combination (5) of these MO's. The stabilisation

$$
\psi_{\mathrm{DA}}=a \phi_{\mathrm{D}}+b \phi_{\mathrm{A}}
$$

energy of a complex may be expressed ${ }^{3 a}$ as in (6).

$$
E_{\text {stab }}=b^{2} D-b^{2} A-2 a b \beta_{D A}+b^{2} V e s
$$

$D$ Is the energy of the $(\mathrm{HOMO})_{D}$ and $A$ is the energy of the (LEMO) $)_{A} \cdot \beta_{D A}$ Is an energy term containing the resonance interaction between donor and acceptor. $-V e s$ Is the contribution of the Coulomb energy.

s3 R. L. Flurry, I. Phys. Chem., 1965, 69, 1927.

34 R. L. Flurry, J. Phys. Chem., 1969, 73, 2111.

35 G. Briegleb, 'Electronen-Donator-Acceptor-Komplexe, chap. IX, Springer-Verlag, Berlin-Göttingen-Heidelberg, 1961.
Flurry did not take into consideration the stabilisation by polarisation and dispersion forces, which can be accounted for by an extra no-bond energy term $G_{0}$ as in equation (7).

$$
E_{\text {stab }}=b^{2} D-b^{2} A-2 a b \beta_{D \Lambda}+b^{2} V e s+G_{0}
$$

Several authors ${ }^{35}$ found that for many series of complexes containing similar donors with the same acceptor the stability (equilibrium constants) of the complexes are linearly related to the ionisation potential or the energy of the charge-transfer transition, but are on the whole rather independent of other factors. Therefore, it seems justified to assume that in such series the degree of charge-transfer, $\beta_{\mathrm{DA}}, V e s$, and $G_{0}$ remain nearly constant. Thus we obtain equation (8),

$$
E_{\text {stab }}=b^{2} D+\mathrm{C}_{\mathbf{1}}
$$

where $C_{1}$ is constant. If in such series of complexes variations in the equilibrium constant $K^{\mathrm{AD}}$ are mainly due to changes in energy rather than in entropy or the entropy changes linearly with the enthalpy, ${ }^{36} \Delta G$ is proportional to $\Delta H$ for the whole series and we may write equation (9). According to Koopmans'

$$
R T \ln K \approx b^{2} D+\mathrm{C}_{1}
$$

theorem $-D$ is equal to the ionisation potential $I_{\mathbf{P}}$ of the donor. ${ }^{37}$ Thus we obtain equation (10). Because

$$
R T \ln K \approx b^{2} I_{\mathrm{p}}+\mathrm{C}_{1}
$$

the linear relationships, found for most complexes with anisoles or methylbenzenes as donors, also include complexes with corresponding biphenyl derivatives, it seems justified to assume that charge-transfer and nobond interactions in biphenyl complexes are similar to those in complexes with corresponding half-molecules. In that case, the assumption that $\Delta_{i}$ [in equation (2)] does not vary by introduction of a phenyl residue in a donor will be correct. Changes in $\Delta_{0}$ will then only be due to differences in $\Delta_{a}$, caused by the anisotropy of the phenyl residue introduced.

It is clear that within a series of complexes with the same acceptor and only anisoles or methylbenzenes as donors $\Delta_{\mathrm{a}}$ ought to be almost constant, as found.

Finally, the deviations from the linear relationship found in Figures $1-3$ for the hindered biphenyls (13), (15), (16), and (34), (35), and (36) can be ascribed to the primary steric effect. Obviously the steric requirements of fluoranil are smaller than those of trinitrobenzene; the deviations are smaller in Figure 3 than in Figure 1. According to expectation, (35) and (36) deviate more than (34), and (16) more than (13). However, the deviation of (15) both with fluoranil and trinitrobenzene is surprisingly large.

se For complexes of trinitrobenzene with the methylbenzenes $\Delta S$ is approximately constant, while for the complexes of fluoranil $\Delta S$ varies considerably but almost linearly with $\Delta H ; \mathrm{M}$. I. Foreman, R. Foster, and C. A. Fyfe, J. Chem. Soc. (B), 1970, 528.

${ }^{37}$ T. Koopmans, Physica, 1933, 1, 104. 
All other deviations [(8), (11), (17)], remarkably enough in the opposite direction, concern donors in which a methoxy-group is enclosed, between two methyl substituents. Foster et al. ${ }^{26}$ reported a non-linear relation

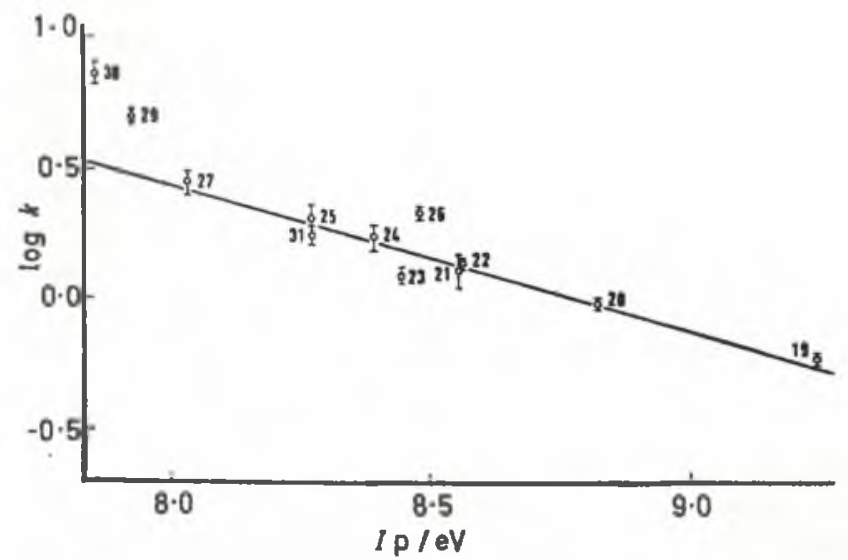

FIgURE 4 Plots of $\log K$ for a series of trinitrobenzene complexes against the ionisation potentials $\left(I_{p}\right)$ of the donors. The numbering corresponds to the donors listed in Table 3

between $\log K$ values and ionisation potentials for complexes between trinitrobenzene and methylbenzenes. A similar plot (Figure 4) reveals that the deviations concern just those donors in which at least three vicinal methyl substituents are present (1,2,3-trimethyl- and especially pentamethyl- and hexamethyl-benzene) whereas, e.g., biphenyl falls on the straight line. $\left(I_{\mathrm{p}}\right.$ values are determined by photoionisation.)

Crowding of substituents in the donor may cause changes in Coulomb and resonance interaction within a series of otherwise similar complexes.* For complexes of such donors, the supposition that the contribution of $\Delta_{i}$ to $\Delta_{0}$ [equation (2)] is constant will not be fully justified.

A second argument can be derived from a comparison between $K^{\Delta D}$ values for complexes with varying acceptors. Generally the trinitrobenzene complexes with methoxy-substituted donors have smaller $K^{\mathrm{AD}}$ values than those of picric acid, but with methylated donors (benzenes or biphenyls) the difference is very small or even in the opposite direction. This may be explained by hydrogen bonding between the acidic proton of picric acid and the ether oxygen of the methoxy-group. With donors (8), (11), and (17) this trend is not found; clearly the acidic proton cannot approach the methoxygroup sufficiently.

Proton $\Delta_{0}$ Values.--For reasons mentioned above it is expected that within a series of complexes with the same acceptor and similar donors, an almost constant value of $\Delta_{0}$ will be observed, so long as the variation in the donors causes no primary steric effect or accumulation

\footnotetext{
* In a plot of $v_{\mathrm{CT}}$ values of the trinitrobenzene complexes with the methylbenzenes against $I_{\mathrm{p}}$ of the donors, (29) and (30) are found to deviate substantially. This corroborates the argument that the deviations are due to variations in the energy terms mentioned.
}

of vicinal substituents in the donors. Tables $1-4$ show that this expectation is justified.

For the complexes of trinitrobenzene with the anisoles (1)-(10), excluding (8), an average value of $\Delta_{0}\left(\Delta_{0}{ }^{\text {av }}\right)$ of $92 \mathrm{~Hz}$ is found. Corresponding results are observed for the other series: for picric acid complexes of anisoles $\Delta_{0}{ }^{\text {av }}$ is $89 \mathrm{~Hz}$ (almost equal to the value for trinitrobenzene complexes), and for trinitrobenzene and picric acid complexes of the methylbenzenes $\Delta_{0}{ }^{\mathrm{av}}$ is 105 and $112 \mathrm{~Hz}$ respectively.

Because in these series $\Delta_{\mathrm{i}}$ and $\Delta_{\mathrm{a}}$ remain constant no information about the structure of the complexes can be obtained from these data. With the help of tables ${ }^{21}$ values of $\Delta_{\mathrm{a}}$ can be calculated for several models (Figure 5). The results show that, so long as a parallel orientation is maintained, $\Delta_{\mathrm{a}}$ is almost insensitive to displacements of the acceptor relative to the donor.

For the calculations a distance between donor and acceptor of $3.3 \AA$ is taken, as found in solid complexes; ${ }^{12,13}$ the $\mathrm{C}-\mathrm{H}$ bond-length is $1-09 \AA$ and the radius of the benzene ring $1.39 \AA$. In structure (II) the displacement relative to (I) is $1.09 \AA$ (a C-H bondlength) and in (III) 2.13 $\AA$. Apparently the influence of ring currents $\left(\Delta_{\mathrm{a}}\right)$ is less than half the total effect $\Delta_{0}$.

Because the complexes of the non-hindered biphenyl derivatives are similar to those of the corresponding ' half' molecules, the increase in the $\Delta_{0}$ values for the

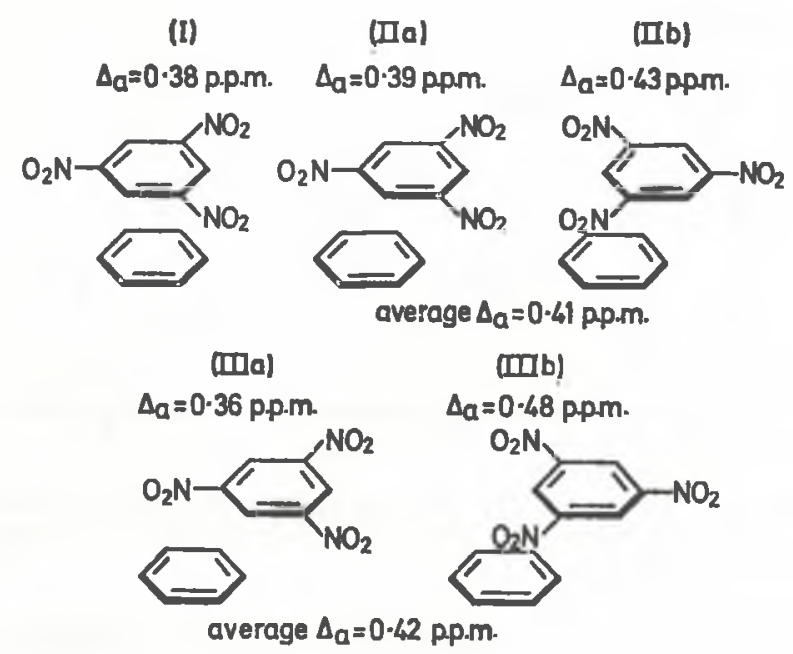

FIGURE 5 Various model structures for a trinitrobenzenebenzene complex

biphenyl complexes can be ascribed to an extra ringcurrent effect $\left(\Delta_{\mathrm{B}}{ }^{\mathrm{\theta}}\right)$ of the second ring (11).

$$
\Delta_{0}=\Delta_{\mathrm{i}}+\Delta_{\mathrm{a}}+\Delta_{\mathrm{a}}^{\mathrm{e}}
$$

Table 6 compares the $\Delta_{0}$ values of the various biphenyl complexes and the $\Delta_{0}{ }^{\text {av }}$ of the corresponding 'half' molecules. For the non-hindered biphenyl donors (14), (31), (32), and (33) $\Delta_{0}-\Delta_{0}{ }^{\mathrm{av}}=\Delta_{\mathrm{a}}^{\mathrm{e}}$ is $18 \pm 1 \mathrm{~Hz}$ in the trinitrobenzene series and $14 \pm 1$ in the picric acid series. From calculations of $\Delta_{\mathrm{a}}^{\mathrm{e}}$ for 
three models [Figure 6; formulae (IV), (V), and (VI), corresponding with (I), (II), and (III), respectively] it appears that the experimental values of $\Delta_{a} e$ agree quite well with the one calculated for (IV) $(16 \mathrm{~Hz}$, Table 7). The deviations for (V) and (VI) are appreciable. For the calculations the same parameters were used as above. The angle of twist of the nonhindered biphenyl is taken ${ }^{38}$ as $20^{\circ}$ and the central $\mathrm{C}-\mathrm{C}$ bondlength ${ }^{39}$ as $1.48 \AA$.

Because of the similarity between the complexes of the non-hindered biphenyls and their corresponding ' half' molecules it seems very probable that in both cases an aromatic ring of the donor and the aromatic

TABLE 6

Comparison of the $\Delta_{0}$ values of the biphenyl complexes of trinitrobenzene and picric acid with the average values of $\Delta_{0}\left(\Delta_{0}{ }^{2 \nabla}\right)$ of their corresponding 'half' molecules

Acceptor, trinitrobenzene

(13) 2,2'-Dimethyl-4,4'-dimethoxybiphenyl

(14) 3,3'-Dimethyl-4,4'-dimethoxy- 111 biphenyl

(15) $2,2^{\prime}, 5,5^{\prime}-$ Tetramethyl $^{-4,4^{\prime}-} \quad 65$ dimethoxybiphenyl

(16) $2,2^{\prime}, 6,6^{\prime}$-'Tetramethyl-4, $4^{\prime}-$ dimethoxybiphenyl

(17) $3,3^{\prime}, 6,5^{\prime}$-'Tetramethyl-4, 4'dimethoxybiphenyl

(31) Biphenyl

(32) 3,3'-Dimethylbiphenyl

(33) 4,4'-Dimethylbipheny?

(34) 2,2'-Dimethylbiphenyl

(35) $2,2^{\prime}, 4,4^{\prime}, 6,6^{\prime}$-Hexamethylbiphenyl

(36) $2,2^{\prime}, 6,6^{\prime}$-Tetramethylbiphenyl 76

$$
\text { Acceptor, picric acid }
$$

(13) 2,2'-Dimethyl-4,4'-dimethoxy- 54 biphenyl

(14) 3,3'-Dimethyl-4,4'-dimethoxy- 102 biphenyl

(15) $2,2^{\prime}, 5,5^{\prime}$-Tetramethyl-4,4'- 65 dimethoxybiphenyl

(16) $2,2^{\prime}, 6,6^{\prime}$-Tetramethyl $-4,4^{\prime}$ dimethoxybiphenyl

(17) $3,3^{\prime}, 5,5^{\prime}-$ Tetramethyl-4,4'dimethoxybiphenyl

(31) Biphenyl

(32) 3,3'-Dimethylbiphenyl

(33) 4,4'-Dimethylbiphenyl

(34) 2,2'-Dimethylbiphenyl $2,2^{\prime}, 6,6^{\prime}$-Tetramethylbiphenyl

a Average value of (31), (32), (33). ${ }^{b} \Delta_{0}$ Of the corresponding 2,6-dimethylanisole complex.

ring of the acceptor have a coaxial conformation, in agreement with Mulliken's principle of maximum overlap.

On account of the discussion of $K$ values a completely analogous structure for the complexes of donor (17) (in which the methoxy-group is flanked by two methyl substituents) is not certain. However, a comparison with the complexes of 2,6-dimethylanisole reveals a difference in $\Delta_{0}$ values $(19 \pm 1)$ similar to those of the complexes discussed above. Consequently, also in this case the structure can probably be described by model (IV), possibly with a preference for conformation (IVa).

In the complexes of the hindered biphenyls the structure is influenced by a primary steric effect, so less

\section{TABLE 7}

Calculated values of $\Delta_{\mathrm{a}} \mathrm{e} / \mathrm{Hz}$ at $100 \mathrm{MHz}$ for various conformations and angles of twist of the biphenyl donors
Angle of twist
Structure (IVa)
Structure (IVb)
Average $\Delta_{\mathrm{B}}{ }^{\circ}$ in $(\mathrm{IV})$
Structure (Va)
Structure $(\mathrm{Vb})$
Average $\Delta_{u^{\circ}}$ in $(\mathrm{V})$
Structure (VI)

$\begin{array}{rrrr}0^{\circ} & 20^{\circ} & 70^{\circ} & 90^{\circ} \\ & 20 & -13 & -17 \\ & 12 & -3 & -7 \\ & 16 & -5 & -12 \\ & +6 & -9 & -11 \\ & +3 & -1 & -7 \\ & +4.5 & -5 & -9\end{array}$

straightforward conclusions about the structure can be drawn.

Table 6 shows that $\Delta_{0}$ values are substantially smaller than $\Delta_{0}{ }^{a v}$ of the corresponding ' half' molecules. The

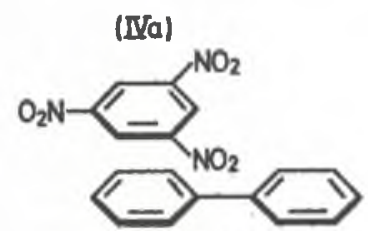

(Va)

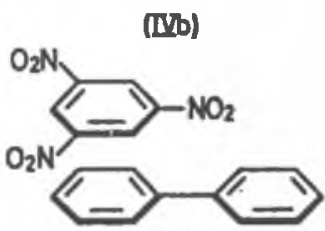

(Ya)
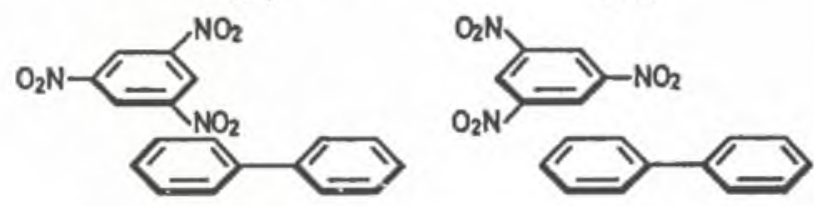

(i)

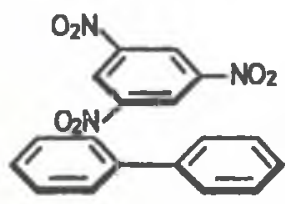

FIGURE 6 Various model structures for a trinitrobenzenebiphenyl complex

experimental values of $\mid \Delta_{0}-\Delta_{0}$ av $\mid$ are much larger than is calculated for models (IV) and (V), even if a much larger angle of twist $\left(70\right.$ or $\left.90^{\circ}\right)$ is taken ${ }^{38}$ (Table 7).

Owing to these large angles of twist in the biphenyl donors the acceptor position will be approximately as in (V) [possibly with a preference for (Va)]. Such a change in conformation of the complex causes undoubtedly changes in $\Delta_{i}$, which would also contribute to the relatively low $\Delta_{0}$ values.

Remarkably, the values of $\Delta_{0}$ of the hindered biphenyls decrease more if the donor possesses a 4-methoxy-group [compare (13) with (34), and (16) with (35) and (36)].

ss H. Suzuki, Bull. Chem. Soc. Japan, 1959, 82, 1350.

so O. Bastiansen, Acta Chem. Scand., 1949, 8, 408. 
On the contrary the primary steric effect is smaller for (13) and (16) (Figures 1-3).

In conformation (V) the acceptor interacts primarily with the 3-, 4-, and 5-positions of the biphenyl donor. When a methoxy-group is substituted in the 4-position, there may be a strong local interaction of the acceptor with the methoxy-group. Moreover, there is a high electron density at the 3- and 5-positions owing to the mesomeric effect of the methoxy-group. Both effects enhance charge-transfer interactions in the complexes of the hindered methoxy-substituted biphenyls. The local interaction of the acceptor with the methoxy-group might result in an extra decrease in $\Delta_{i}$ in addition to the decrease caused by the change in structure of the complex.

Fluorine $\Delta_{0}$ Values.-The $\Delta_{0}$ values of fluoranil complexes $\left({ }^{19} \mathrm{~F}\right.$ resonance) are about three times sa large as the corresponding values $\left({ }^{1} \mathrm{H}\right.$ resonance) of trinitrobenzene or picric acid complexes. ${ }^{19} \mathrm{~F}$ Chemical shifts are, however, much more dependent on changes in charge density than proton shifts ${ }^{40}$ and rather insensitive to variations in ring-current effects.

Therefore, the differences in $\Delta_{0}$ for various complexes are due to differences in $\Delta_{\mathrm{i}}$ rather than in $\Delta_{\mathrm{a}}$ and less apt for a study as in this paper.

We thank Mrs. M. J. B. P. J. Hoevenaars-van Hoof and Mr. J. M. F. Mous for n.m.r. spectra and Drs W. A. Doesburg for help in statistical analysis.

[1/2133 Received, 11th November, 1971]

${ }^{\prime}$ A. Saika and C. P. Slichter, J. Chem. Phys., 1954, $22,26$. 
-

- 